\title{
ELS FONAMENTS DE LA IRONIA CALDERSIANA: LA GLÒRIA DEL DOCTOR LARÉN*
}

\author{
THE BASIS OF CALDER'S IRONY: \\ LA GLÒRIA DEL DOCTOR LARÉN
}

\section{Carme Gregori Soldevila \\ Universitat de València \\ Carme.Gregori-Soldevila@uv.es}

Resum: L'article passa revista a les diferents modalitats de la ironia que són presents a La Glòria del doctor Larén (1936), la primera novel-la de Pere Calders: les reflexions metaficcionals a càrrec dels narradors i dels personatges i altres recursos irònics a l'abast del narrador en l'exercici de les seues funcions, la ironia de l'autor en el prefaci, les ironies de situació, les ironies verbals i les paròdies. L'anàlisi mostra, a través de la diversitat i la recurrència de les ironies que hi apareixen, que $L a$ Glòria del doctor Larén posa les bases de la ironia que identificarà la poètica de l'autor i ho fa amb el caràcter, les funcions i l'estil característics de la producció de l'etapa de maduresa.

Paraules clau: Ironia, metaficció, paròdia, Pere Calders, La Glòria del doctor Larén.

Abstract: This paper reexamines the different types of irony present in La Glòria del doctor Larén (1936), Pere Calders's first novel. These include meta-fictional reflections by narrators and characters and other ironic means within reach of the narrator in the exercise of his functions, the author's irony in the preface, irony of situation, verbal irony and parody. Through the diversity and recurrence of its ironies, the analysis shows that La Gloria del doctor Larén provides the basis

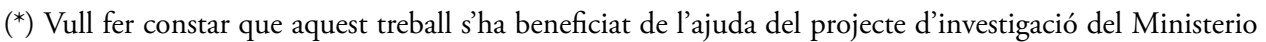
de Economía y Competitividad FFI20I3-4II47-P titulat La ironía en la literatura catalana desde el "Modernisme" hasta 1939.

L'estudiós interessat pot consultar en línia el banc de dades bibliogràfic del grup d'investigació sobre estudis d'ironia, paròdia i pastitx en la literatura catalana des de l'inici del segle xx fins a l'actualitat a l'adreça: <http:www.uv.es/ironialitcat>. 
Carme Gregori Soldevila

Els fonaments de la ironia caldersiana: La Glòria del doctor Larén

for identifying the author's poetic irony with the character, functions and style characteristic of Calder's production of maturity..

Key words: Irony, metafiction, parody, Pere Calders, La Glòria del doctor Larén.

$\cos \cos$

\section{LA GLÒRIA DEL DOCTOR LARÉN I LA IRONIA CALDERSIANA}

L'any 1952, en el procés de preparació del volum de contes que acabarà sent Cròniques de la veritat oculta, Pere Calders, amb l'objectiu de fer-li conèixer la seua producció anterior, va fer arribar a Joan Triadú el seu primer llibre editat, El primer arlequí, així com els contes publicats a Mirador i Meridià durant la guerra i altres contes inèdits (Calders 2013: 34-35). Significativament, Calders no incloïa en la mostra ni la seua primera novel.la, La Glòria del doctor Larén, publicada en 1936, el mateix any que El primer arlequí, ni tampocla crònica de guerra Unitats dexoc; més encara, l'escriptor se'n distanciava quan, assabentat que havien arribat a mans dels crític, escrivia (2013: 37):

sé pel meu pare que ja heu retornat a Barcelona, que us heu entrevistat amb ell i que teniu ja els meus originals. Per cert que em diu que us ha lliurat també La Glòria del doctor Larén i Unitats de xoc. La primera és tot un pecat de joventut i em ruboritza el sol pensament que pugueu llegir-la; la segona em sembla que no té res a veure amb el llibre que ens proposem editar. Sigueu indulgent...!

L'autor va mantenir durant molts anys les reserves envers la seua primera novel.la, esdevinguda el "parent pobre en el repartiment de l'herència de Calders» (Aulet 1997: 69): a diferència de la resta de la producció de preguerra, La Glòria del doctor Larén no va ser incorporada a les Obres Completes i va ser reeditada, molt tardanament, el 1994, només pocs mesos abans de la mort de l'escriptor. A pesar d'aquest refús, i d'alguna opinió crítica que la va considerar una "obra menor»" (Vallverdú I96r: 32), la major part dels estudiosos de la literatura caldersiana convenen avui a assenyalar que aquesta novel-la conté, certament en estat embrionari, però ja definits en aspectes essencials, alguns dels trets que distingiran l'obra de maduresa de l'autor. En aquest sentit, Joan Melcion (1996: 252-253) ha remarcat la importància que hi té, ja en aquesta primera

I. Cal advertir que Francesc Vallverdú, el crític que així es pronunciava sota el pseudònim Ramon Roig, ha reconegut la injustícia d'aquesta opinió desfavorable (I994: 9-IO) 
novel.la, el joc irònic sobre els mecanismes narratius, un procediment nuclear en la poètica de l'autor que assolirà la versió més ambiciosa i arrodonida de la proposta a Ronda naval sota la boira:

[Calders] buscarà fórmules pròpies per buscar una sortida personal al capgirament de la funció representativa de la literatura. El distanciament irònic respecte a la realitat, però també respecte a la representació de la realitat, en aquest cas la mateixa narració, constituirà la seva fórmula bàsica. [...] ningú com Calders no ha sabut elevar aquesta fórmula a categoria literària fins al punt d'esdevenir la matèria primera de tot el seu univers de ficció.

Així, doncs, Melcion atorga a la ironia una importància clau en la definició inicial de la narrativa caldersiana. Entre els estudiosos de l'obra de l'autor, només Amanda Bath es decanta per negar explícitament el component irònic en La Glòria del doctor Larén, almenys en la modalitat que identifica com a "humor textual» (Bath 1987: 84):

L'humor textual de La Glòria... és intensament visual [...]; Calders, en aquest treball, no empra humor lingüístic (jocs de paraules, acudits o dites populars) i poques vegades recorre als tipus d'humor més intel-lectualment exigents, com és el cas de la ironia.

En general, però, la tònica més habitual en la bibliografia dedicada a aquesta primera novel.la fa coincidir en l'anàlisi els components de l'humor i de la ironia, sense destriar-ne clarament l'abast ni el caràcter. Així, per exemple, Agustí Pons (I998: 92-93) considera que «l'humor constitueix el tret més específic de La Glòria del doctor Larén», alhora que assenyala que aquest humor «tot ell està amarat d'una ironia subtil i demolidora». En un autor com Pere Calders, l'espai de confluència entre humor i ironia és més gran que en els casos en què la coloració afectiva de la ironia adopta tonalitats allunyades del riure, com ara la dramàtica; per tant, la possible confusió dels registres és susceptible de produir-se amb major facilitat. No obstant això, la claredat conceptual i el rigor metodològic exigeixen destriar la ironia del territori, certament vague i no exempt de problemes identitaris, de la comicitat. En la ironia domina el caràcter reflexiu, en contraposició a la funció principal de divertiment de l'humor. Schoentjes (200I: 222-223), per exemple, vincula el riure, propi de la comicitat i l'humor, a l'esfera afectiva, mentre que la ironia pertany a l'àmbit dels fenòmens intel.lectuals: el riure apel.la als sentits i als sentiments, deixant en suspens la raó; la ironia, per contra, té uns mecanismes de funcionament racionals. A més de l'índole intel-lectual, els teòrics coincideixen a atorgar-li un altre tret distintiu que la distingeix netament de la comicitat i l'humor: la dissimulació (Muecke I970: 36; Ballart 1994: 442; Schoentjes 200I: 223). L'humor és directe i obert, mentre que la dissimulació pròpia de la ironia converteix aquesta en un mode de dicció indirecta, en el qual el fingiment adoptat instaura una distància higiènica entre l'ironista i allò que diu o 
Carme Gregori Soldevila

Els fonaments de la ironia caldersiana: La Glòria del doctor Larén

presenta i equival, per tant, a una forma de control. Els recursos a l'abast de l'ironista per a dissimular la seua activitat inclouen "procedimientos retóricos, ficcionalización de su propia persona, dramatización de la acción, etc.» (Ballart 1994: 319).

La crítica sobre La Glòria del doctor Larén s'ha centrat bàsicament en l'anàlisi dels procediments mitjançant els quals la novel.la, a l'interior de l'univers diegètic, posa en qüestió les possibilitats i els límits de la representació de la realitat per part de la literatura (Campillo 1996; Melcion 1996; 2003; Aulet 1997; Balaguer 2003; Martínez Gil 2003). Tot i no atorgar-li sempre un fonament $o$ un caràcter irònic, la línia interpretativa dominant ha assenyalat amb claredat la condició autoreflexiva d'una novel.la que posa al centre dels seus interessos la denúncia de l'arbitrarietat i l'artifici de les convencions literàries. El que, des d'una perspectiva irònica, identificaríem com a component metaficcional. En el present treball, ens proposem passar revista a les diferents modalitats de la ironia que són presents a la primera de les novel.les de Pere Calders: les reflexions metaficcionals a càrrec dels narradors i els personatges, però també la resta dels recursos irònics a l'abast del narrador en l'exercici de les seues funcions; la ironia de l'autor en el prefaci; les ironies de situació, les ironies verbals i les paròdies. Pensem que, a la fi del recorregut, la recurrència i la diversitat de les ironies analitzades ens permetran afirmar, des d'unes conclusions ancorades en l'estudi detallat del text, que La Glòria del doctor Larén posa les bases de la ironia que identificarà plenament la poètica caldersiana en la seua etapa de maduresa.

\section{EL PREFACI AUCTORIAL IRÒNIC}

Calders encapçala la novel.la amb un prefaci auctorial original autèntic assumptiu (Genette 1987: 150-I8I) que cal atribuir, sense vacil.lacions, a l'escriptor real, el qual signa, a la fi del «Pròleg», amb les seues inicials. La funció irònica d'aquest prefaci ha estat assenyalada a bastament per la crítica, que, de manera general, ha coincidit també a proclamar-ne l'originalitat i l'encert. ${ }^{2}$ En paraules de Vallverdú (I994: II-I2):

De fet, tal com han destacat tots els crítics des d'Osvald Cardona fins a Amanda Bath, un dels ardits més enginyosos de la novel-la és precisament el breu pròleg de l'autor, sens dubte entre els més brillants de les lletres catalanes modernes, per la concisió, la intencionalitat i

2. Agustí Pons en seria una excepció, ja que els termes amb què s'hi refereix donen peu a pensar que interpreta en clau no irònica el prefaci: «És un pròleg que sembla donar resposta a les crítiques que Pere Calders havia rebut i, sobretot, a les que encara havia de rebre» (1998: 90). 
l'agudesa. ${ }^{3}$ Una novel.la encapçalada amb un pròleg d'aquesta consistència en el qual Calders s'avança irònicament a les objeccions de la crítica, decididament no pot defraudar.

Aulet i Balaguer, per la seua banda, consideren que cal entendre la clau irònica del pròleg en relació a la dimensió metaficcional de la novel.la. Per a Aulet, es tractaria d'indicar que "la narració, en el fons, ja ha començat» perquè se'ns presenta "un primer punt de vista sobre com explicar la història» (1997: 70); Balaguer (2003: 343-344) insisteix a associar l'ús irònic del prefaci amb una crida d'atenció sobre el tema de l'obra: el procés narratiu de construcció de la història i la funció que hi té assignada el lector.

El text caldersià s'ha d'entendre com una manifestació, en to irònic, d'una de les funcions habituals del prefaci auctorial: la captatio. L'autor adopta un aire d'inseguretat defensiva, que contraposa, amb humilitat exagerada, a uns models que fa explícits (I5): ${ }^{4}$

Sempre m'han causat una profunda admiració els autors que saben presentar elegantment els seus llibres. Tinc el pressentiment que la meva vocació literària es troba encallada d'antuvi per aquesta dificultat inicial: saber presentar les pròpies obres. D'altra banda, no estic gaire segur que això sigui absolutament necessari. Heus ací, entre altres, els inconvenients de la infeliç incipiència literària.

Com he envejat, a través de llargues temporades, el pròleg de Josep Carner per a Els fruits saborosos i el de Josep Pla per a Coses vistes! Darrerament m'ha despertat l'avidesa de plagi la magnífica presentació que fa Joan Oliver del seu drama Allò que tal vegada séesdevingué.

Podem identificar l'actitud irònica exhibida per l'escriptor, en relació al'enunciat, amb el tipus d'ironia que Muecke denomina «self-disparaging irony» (I969: 87-9I), en la qual l'ironista se'ns presenta sota l'aparença d'un personatge que se subestima o automenysprea, tot i que la disfressa no ens impedeix centrar l'atenció en l'autèntic objecte de la ironia que no és, per descomptat, la pretesa ignorància o inutilitat de l'ironista. La subestimació aparent es veu reforçada, en el pròleg a La Glòria del doctor Larén, per la ingènua fantasia del triomf sobre una crítica adversa, encara inexistent, en una polèmica imaginària, fruit únicament dels temors, també irònicament subratllats, de l'escriptor. En el pròleg de Calders, l'objecte de la ironia és precisament la funció justificativa dels prefacis auctorials, ara completament hipertrofiada. A la fi, però, l'autor, encara que siga mitjançant el subterfugi manifest d'erigir-se en jutge

3. Osvald Cardona, en una ressenya publicada en el moment d'aparició de la novel.la, comentava: «al pròleg, digne del llibre que el segueix, ja anuncia que alguns defectes li "apareixen com a subtils ardits literaris". I s'aproxima a l'encert de la suposició, perquè aquests defectes o gràcies són plenament nivellats» (I937:5). També Joan Triadú recordava el prefaci caldersià com «un dels pròlegs més divertits que un escriptor català hagi dedicat mai a una obra seva» (1963: 27).

4. Totes les citacions de La Glòria del doctor Larén corresponen a l'edició de i994, la referència completa de la qual apareix en la bibliografia final. Al llarg de l'article, només en consignarem les pàgines entre parèntesis.

Caplletra 60 (Primavera, 2016), pp. 163-182 
Carme Gregori Soldevila

Els fonaments de la ironia caldersiana: La Glòria del doctor Larén

parcial —com a "pare de la criatura»—, acabarà per executar la mateixa justificació que denunciava irònicament. D'igual manera, el tractament antifràstic dels «ardits literaris» com a «defectes» li servirà per a reivindicar irònicament les bases de la seua poètica (I6):

La manca d'unitat l'atribueixo a una despreocupació que em permet d'alimentar la illusió de creure'm al corrent d'una branca de la moderna novel-lística europea; l'estil inconnex i desorientat és una manera volguda i meditada d'accentuar la meva personalitat, subtil i garneua, d'aquesta manera que sempre m'ha agradat tant.

\section{LES IRONIES DELS NARRADORS}

La Glòria del doctor Larén presenta dos nivells narratius: un primer nivell en el qual un narrador extra-homodiegètic s'adreça a un narratari no denominat per contar-li la història de la seua relació amb un individu cínic amb qui comparteix la història de Glòria i el doctor Larén; i un segon nivell en el qual, com a doble narrador, el narrador del nivell extradiegètic esdevé narrador intradiegètic quan s'adreça al seu interlocutor-personatge, qui fa la funció de narratari intradiegètic, per relatar-li la història del doctor Larén $i$ la seua esposa Glòria $i$, alhora, el personatge que funciona com a narratari es converteix posteriorment en narrador, igualment intradiegètic, quan narra, en el capítol quart, la seua versió de la història dels personatges protagonistes —Larén i Glòria—, amb l'anterior narrador convertit ara en narratari.

Els narradors, en l'exercici de les funcions que els són pròpies, fan ús de la ironia mitjançant diversos procediments. Així, per exemple, entre les funcions extranarratives (Genette 1972: 26I-265), la funció de control amb què el narrador intradiegètic primer fa referència al text narratiu, per qüestionar-ne la idoneïtat, és a dir, per posar en entredit la seua pròpia tasca com a narrador: «considerant la història del doctor i la Glòria, vaig trobar que explicada per mi perdia consistència, i es tornava terriblement vulgar i taujana» (p. 39); o la funció testimonial amb què el narrador intradiegètic segon dóna garanties d'imparcialitat, comparant-se ell mateix amb «un cronista mercenari» (p. 4I), per a reconèixer més tard que, en realitat, ha fet servir els recursos més adequats a les exigències narratives: «no veig cap inconvenient a reforçar amb una certa imaginació els punts flacs de les històries, procedir que va sempre a benefici de l'auditori. A més, som llatins i mentiders fins a la medul.la» (p. 97).

Ambdós narradors també fan servir irònicament la digressió reflexiva: en el capítol cinquè, s'acusen mútuament d'aprofitar els mecanismes de la ficció per a construir les respectives versions de la història del doctor Larén i Glòria, en una conversa de marcat 
caràcter metaficcional: el primer, per exemple, qüestiona la font d'on el segon ha pogut extraure els materials per a reconstruir els monòlegs interiors dels personatges, per a concloure que «els personatges de la vostra narració semblen moguts constantment per la mà d'un novel-lista inexpert i arbitrari, preocupat per bastir una gran carcassa fofa al voltant d'una intriga petita i falsa» (p. 96). El segon narrador, per la seua banda, contraataca (p. 97) amb uns arguments semblants:

\footnotetext{
Quan vós, que heu confessat no conèixer més que superficialment la personalitat del doctor, explicàveu en el transcurs de la vostra narració que, en l'interior de l'ambulància que conduïa cap a la clínica el cos inanimat de la Glòria, Larén es deia "que fer l'amor a una noia com aquesta devia ser com ensenyar a muntar a cavall una copa de finíssim cristall de Bohèmia”, ¿us cenyíeu a una veritat estricta o bé us deixàveu emportar per la fantasia?
}

En aquest sentit, la metaficció, pel fet mateix de posar de manifest les convencions que el gènere exigeix de mantenir implícites perquè puguen resultar plenament efectives, és substancialment irònica, perquè instaura una distància entre la pretesa il.lusió mimètica de la ficció i la consciència d'artifici. El component metaficcional també es fa present en una altra escena, en aquest cas, amb el narrador extra-homodiegètic i el doctor Larén com a personatges: Larén — qui arriba a identificar-se com a «protagonista de novel.la» (p. II5) — demana al narrador que escriga la seua història, pretensió a la qual aquest es nega, després d'intercanviar opinions sobre l'interès i la finalitat de la narració que en podria resultar. Una vegada més, l'atenció se centra en la construcció de la història, en comptes de fer-ho en la narració de la història. A més, un altre element subratlla la dimensió metaficcional de l'episodi: el narrador renuncia a narrar una història que, de fet, els lectors estem llegint, contada per ell, amb la consegüent crida d'atenció cap a l'artifici de la ficció narrativa.

En contraposició al narrador intradiegètic primer, el qual creu en la bondat «com a condició inherent a la naturalesa humana» (p. I8), el narrador intradiegètic segon opina que és la maldat la que predomina en les relacions humanes $i$, en conseqüència, adopta una actitud irònica, marcada pel distanciament, en la seua visió del món. En l'exercici de la funció ideològica, mitjançant la qual el narrador opina sobre els personatges, avaluant-ne pensaments, paraules $i$ accions, la ironia permetrà denunciar-ne el comportament inapropiat o fer-ne una valoració negativa. Així, la descripció de la família del doctor Larén ens n'ofereix un clar exemple: el pare ens és presentat com un "provincià infeliç i ric fins a la poca-solta» que fa servir «una estratègia pueril, que fluctuava entre l'adulació i la hipocresia» (pp. 45-46); i la mare és una «dama buida i encartronada, carregada de romanços» (pp. 47) que té com a prioritat màxima en la vida dissimular un defecte al coll. Les decisions del doctor Larén també són objecte

Caplletra 60 (Primavera, 2016), pp. 163-182 
d'una crítica contundent i distanciada per part del narrador: la fugida per a escapar del xantatgista és qualificada d' "absurda determinació», pròpia d'un «exagerat i un ximple» (p. 63). Al seu torn, Glòria no rep un tracte millor, considerada pel narrador «beneita i pseudo-romàntica» (66). Altres personatges, com Donálvez, són igualment desacreditats irònicament pel narrador, el qual considera que canta "cançons idiotes» (p. 72) i dóna «petites conferències imbècils» (p. 78).

La dissonància del narrador en relació als personatges també pot posar-se de manifest a través dels comentaris d'aquest que qüestionen l'adequació de les opinions o actuacions del personatge. Ho podem comprovar amb un exemple: quan Donálvez repta en duel el doctor Larén, el comentari del narrador ironitza, «com si es tractés d'un vulgar periodista francès» (p. 82). O, també: «el doctor esgrimia sovint amb pretensions d'agudesa una teoria» (p. 82), on la tria del terme "pretensions» equival a una desqualificació completa de la credibilitat de Larén per part del narrador.

Un altre recurs irònic a l'abast del narrador consisteix a reproduir un enunciat dels personatges amb l'objectiu de dissociar-se'n, de fer evident la seua crítica i desautoritzar l'individu, grup o norma a qui atribueix l'enunciat. Es tracta d'un dels usos que més clarament mostren el mecanisme de la ironia com a menció, descrit per Sperber i Wilson (1978): la ironia s'expressa no a través de l'enunciat, sinó a propòsit de l'enunciat; qui parla, en comptes d'emprar l'enunciat, el menciona, prenent-hi distància amb la voluntat d'assenyalar-ne la manca de pertinença o de fiabilitat. És el cas, per exemple, de la citació, marcada com a tal entre cometes, d'una expressió que cal atribuir al doctor Larén i a Glòria: «es lliuraren al goig de "viure a fora"» (p. 67), que s'oposa irònicament a la descripció poc entusiasta que fa el narrador del que cataloga com «una d'aquestes cases construïdes de cara a l'estiuejant» (p. 66), un contrast que posa en evidència la manca de criteri dels personatges.

És a dir, en conjunt, el narrador intradiegètic segon, aquell a qui el seu oponent acusa de perforar «la vida amb un etern somriure cínic» (p. I8), adopta l'actitud de l'observador irònic que estableix una distància de seguretat entre ell i allò que són, diuen o fan els personatges de la història que narra, els quals es converteixen en víctimes de la seua ironia.

A banda dels recursos comentats en aquest apartat, lligats a la condició pròpia del narrador i a les seues funcions, el narrador té al seu abast altres mitjans per a fixar un distanciament irònic en relació als personatges o a la història que narra, uns recursos que pertanyen a l'àmbit de les ironies verbals, que seran estudiades en el punt següent. 


\section{LES IRONIES VERBALS}

La hipèrbole és un dels recursos característics de la producció literària de maduresa de Calders (Gregori Soldevila 2005: 268-269) que ja es troba de forma destacada a La Glòria del doctor Larén, amb un notable rendiment irònic en la descripció del personatge femení protagonista. La fragilitat física i espiritual de la Glòria és sotmesa a una amplificació exagerada que n'inverteix la qualitat, canviant la suposada delicadesa per l'absurd i pel ridícul. A més, l'acumulació d'hipèrboles en la descripció del personatge contribueix a intensificar-ne encara més l'efecte. Vegem-ne alguns, d'entre els molts exemples que podríem citar:

És fina i delicada com un mànec de lliri, i sempre ha tingut una salut i una constitució tan estantisses que va haver de portar fins als catorze anys una cotilla ortopèdica, perquè el més lleu cop d'aire li sacsejava tan brutalment la silueta que se li segava la cintura.

[...] Fins després d'haver entrat a l'adolescència, va haver de remoure's al llit amb precaució, perquè un sotrac massa brusc li trencava els ossos (p. 23)

Si «indefugiblement» cal assabentar-la d'alguna cosa massa crua, massa terrenal (l'adolescència té les seves lleis) cal fer-ho en vers i valent-se de les metàfores més delicades.

[...] Pronunciar les paraules «metge» $\mathbf{O}$ «malaltia» en presència seva, equival a envellir-la prematurament (p. 24).

L'emoció que sofria la noia, l’aprimava a la vista, i adquiria una finesa de línia i de color alarmants. Quan va sortir de casa dels seus pares, calçava unes sabates de seda argentada, un 33 ajustat, que donava a la Glòria un caminar cautelós, de caçador d'animals fins, i abans d'arribar a l'església, els peus de la Glòria s'havien amagrit de tres números, i semblava que portés esclops (p. 3I)

La família del doctor Larén tampoc no escapa de la influència de l'augment hiperbòlic. De fet, com bé té cura de precisar el narrador que recupera la història del llinatge del protagonista, «tots els membres de la família dels quals es té memòria han viscut sota el signe de l'exageració» (p. 58). L'oncle n'és un bon exemple; un viatge de poques setmanes a Amèrica té sobre ell unes conseqüències que, en un altre, només haurien estat possibles per l'efecte d'una estada de dècades:

No recordava ni un borrall de català, i parlava amb un accent crioll tan acusat que marejava. Portava a la mà, sempre, una carabassa decorada al foc, plena de mate; assegurava que havia contret el vici d'aquella beguda de tal manera, que privar-lo li hauria representat la mort.

[...] Llegia llibres d'aventures cavalleresques, prenia lliçons d'esgrima per correspondència i es reeducava, a còpia de grans esforços, l'idioma matern, perdut segons paraules d'ell «en l'aridesa de les praderies verges d'Amèrica» (pp. 5I-52)

Aquests antecedents tenen repercussió en el caràcter del jove Larén, les reaccions desmesurades del qual, subratllades pel narrador, instauren un distanciament irònic entre els seus èxits i fracassos i la visió que se'ns n’ofereix (p. 63): 
Carme Gregori Soldevila

Els fonaments de la ironia caldersiana: La Glòria del doctor Larén

Per cada examen bo organitzava uns cicles de festes que empal.lidien el record de les bacanals romanes, i per cada examen dolent iniciava uns llargs períodes de taciturnitat, durant els quals assassinava amb la mirada (per manca, es deia ell, de granades de mà) els components dels tribunals que havien menyspreat els seus mèrits. Va haver-hi un catedràtic d'obstetrícia que per a poder-lo declarar suspens de l'assignatura amb una relativa tranquil-litat d'esperit va fer-se fer una samarreta de cota de malla.

En La Glòria del doctor Larén, el contrast irònic també es vehicula freqüentment a través de l'oxímoron i la paradoxa, dues figures basades en el mecanisme de l'antítesi, molt sovint lligades al funcionament de la ironia. Hi trobem l'oxímoron o associació de dos termes antinòmics escampat al llarg de la novel.la en el discurs dels narradors, amb multitud d'exemples: "petites monstruositats» (p. I8), "poltrones ortopèdiques, angoixoses de tan confortables» (p. 43), "petites intervencions quirúrgiques sense importància, més mortíferes que els accidents d'aviació» (p. 63), «es lliuraven al goig de "viure a fora", respirant fins al fons dels pulmons les bactèries pageses» (p. 67), "una cara d'ase que enamorava» (p. 90), «una coneixença gairebé desconeguda» (p. I05), «un cotxe aerodinàmic magnífic, d'un mal gust oriental» (p. I08). Entre les paradoxes, caracteritzades per la unió o relació d'idees o conceptes antagònics, destaquen, entre altres: el fet que, a la Glòria, "la sola presència del doctor li feia més mal que la malaltia» (p. 25); les conseqüències desastroses que, en comparació amb la cria natural, té la cria d'animals, "organitzada científicament» pel doctor Larén, tant pel que fa a la quantitat, com per la qualitat dels resultats: «les cries obtingudes científicament es diferenciaven de les altres per una notable debilitat progressiva, principis d'una mena de tracoma i anorèxia» (p. 68); o la producció de l'efecte contrari a la pretensió desitjada, quan Glòria té la intenció d'entretenir Muraña: "procurava fer-li menys lentes les hores, llegint-li unes delicadíssimes novel-les cursis, o bé oferint-li els seus serveis com a contrincant en els jocs de dames, o de l'oca, en els quals, en un tergiversament dels papers, la que es distreia follament era la infermera i l'avorrit el malalt» (p. 76). També hi ha algun cas de raonament paradoxal, que es desvia de la lògica racional, tot mantenint una coherència aparent, com ara l'argument que fa servir Larén per a negar credibilitat a la denúncia d'adulteri feta per Donálvez (p. 82):

En qüestions de gelosia conjugal, el doctor esgrimia sovint amb pretensions d'agudesa una teoria que es basava en l'acceptació tàcita que la confiança no té termes mitjos: es concedeix plenament a una persona o se li nega en absolut. Aplicada als matrimonis, aquesta hipòtesi significava que el marit ha de confiar a cegues en l'esposa o desconfiar-ne sense reserves. Al doctor, la Glòria li inspirava una sensació de tranquil.litat i de confort incommovibles, a la qual no estava disposat a renunciar per la delació baixa d'un castellà desconegut. 
A la primera novel.la de Calders, la ironia també apareix sota forma d'antífrasi, la figura de dicció que, en una accepció restrictiva del fenomen irònic, la retòrica clàssica identificava amb la ironia. Podem apreciar la inversió semàntica pròpia de l'antífrasi, per exemple, quan el narrador extra-homodiegètic afirma que ha criticat les idees de Jonathan Swift "davant d'auditoris selectes» (p. I7), en un context que permet inferir amb claredat que ell no els considera pas selectes; o quan qualifica d' «honorable» un club per a, tot seguit, informar sobre «la misèria íntima de la majoria d'aquells senyors" (p. 19), amb uns detalls que obliguen a entendre en sentit contrari l'honorabilitat del club; o, també, en la resposta del narrador cínic, quan sembla concedir al seu contrincant una «mordacitat» que està ben lluny de correspondre amb la seua autèntica opinió (p. 2I):

—_Però creieu que us divertirà un relat que tingui per protagonistes dues persones honrades? - Servit amb la vostra mordacitat, indubtablement.

Les comparacions satíriques són un altre dels recursos al servei de la ironia, amb una alta recurrència a La Glòria del doctor Larén. La delicadesa de la protagonista femenina, per exemple, genera tot un seguit de comparacions caracteritzades per fer servir comparants no pertinents, que rebaixen les qualitats de l'element comparat: "Quina finor de carn! Elàstica com la gutaperxa, i d'una suavitat tàctil com la fècula de patata» (p. 29); "extremava les seves delicades condicions, i no es movia sinó a petits salts, com un ocell adolescent i malaltís» (p. 80). En el primer exemple, l'admiració de la bellesa femenina no concorda amb les característiques dels elements als quals és comparada, d'un marcat prosaisme: una substància gomosa i una mena de midó, amb la consegüent degradació de l'objecte de la comparació. En el segon, la imatge de l'ocell s'adequaria de manera coherent a la delicadesa de la dona, si no fos pel trencament de registre que hi afegeixen els qualificatius «adolescent i malaltís» que n'inverteixen la connotació, en principi, positiva. La ironia es fa patent quan la comparació satírica posa en evidència una exageració que converteix la comparació en absurda; en podem apreciar un cas clar quan Larén, tot pensant en la fragilitat de la Glòria, conclou, amb un raonament citat adès, dins un paràgraf més llarg, comentat en parlar de la digressió reflexiva: «Quina responsabilitat estimar una noia així! Deu ser com ensenyar a muntar a cavall una copa de finíssim cristall de Bohèmia» (p. 29).

Quan la comparació fa servir un terme que se situa en un domini notablement inferior al de l'objecte amb el qual es compara, el resultat és una comparació grotesca, caracteritzada pel caràcter burlesc. A la novel.la de Calders en trobem multitud d'exemples, en el tractament irònic dels personatges: de Larén, entre altres, se'ns diu que «els seus somnis lascius tenien l'aire d'una cavalcada interminable de bacons» 
Carme Gregori Soldevila

Els fonaments de la ironia caldersiana: La Glòria del doctor Larén

(p. 65); el cabell de Glòria, després del tractament contra la sarna, és un pèl que «semblava tenir la qualitat dels que s'arrenquen del ventre les conilles, per fer el jaç dels lludrigons» (p. II2); Donálvez, per la seua banda, té «la pell descolorida i alcalina, com un pneumàtic vell de bibicleta» (p. 7I); o el doctor Larén i el seu antic condeixeble, assidus visitants de cabarets, arriben «a parlar de flancs, de cames, de pits i de conjunts de dona amb la reconeguda competència amb què podria referir-se a les mules un tractant de bestiar» (p. III).

També la metonímia pot assolir una càrrega irònica mitjançant la inclinació grotesca. La «misèria íntima» dels membres del club que visiten el narrador i el seu acompanyant queda reforçada per la seua reducció a la part del cos més estretament vinculada als baixos instints: «aquells senyors, encastats en unes enormes poltrones $\mathrm{o}$ passejant l'abdomen d'una banda a l'altra dels salons» (p. 19).

D'altra banda, les enumeracions que juxtaposen o associen elements de caràcter contradictori o dissemblant poden contenir un sentit irònic quan estableixen un contrast que, sota les aparences, obliga a interpretar l'autèntic significat que hom ha volgut donar-hi. Així, posem per cas, la formulació del xantatge de Bordú al doctor Larén: «en una llarga disquisició que començava amb una cita de Stendhal i acabava amb uns versos de l'Esclasans, exigí el lliurament d'una determinada quantitat" (p. 36), on les referències literàries contrasten irònicament amb l'objecte real del seu ús.

Un dels mecanismes irònics que assolirà la condició de tret definitori en l'obra de maduresa de Calders és la investigació a l'entorn dels sentits latents del llenguatge, a través, per exemple, dels jocs de mots, de la desautomatització dels usos estereotipats o de la interpretació en sentit literal de mots o expressions que hom acostuma a utilitzar en sentit figurat. D'aquesta manera, l'autor explota els desajustaments entre llenguatge i referent i dota paraules i frases d'un sentit imprevist. L'atenció, en aquests casos, es concentra en la materialitat del llenguatge i deixa al descobert l'arbitrarietat de la relació entre els mots i les coses, alhora que produeix un efecte de resemantització perquè obliga a considerar des d'una òptica inhabitual la designació de la realitat. Així, per exemple, si, segons el $D I E C_{2}$, «esgarriacries» és "persona que es complau a posar entrebancs que les coses reïxin», la Glòria es lliura de ple a, literalment, «esgarriar cries» (p. 69) dels animals de la granja. Un altre exemple el trobem quan la Glòria, en assabentar-se de la celebració del duel, en un atac d'histerisme, «es feia uns grans esvorancs a les vestidures» (p. 83). L'expressió «esquinçar-se les vestidures» té el seu origen en un episodi bíblic, concretament, en la reacció de Caifas quan Jesús es declara fill de Déu (Mt 26, 63-65); es tractava d'un gest ritual, signe de dolor i de tristesa, que els jutges havien de fer quan algú blasfemava. A partir d'ací, l'expressió acostuma a utilitzar-se, 
en sentit figurat, quan algú s'escandalitza, però en l'exemple de La Glòria del doctor Larén, retorna al pla literal, amb la consegüent desautomatització de l'ús codificat.

Pere Ballart (1994: 333) posa Calders com a exemple de la varietat d'ironia que fa servir el recurs de la lítote, caracteritzada per la impropietat del to que hom fa servir, clarament inadequat per a referir la mena de fets narrats, la qual provoca un efecte de distanciament a base d'eufemismes o reticències. En efecte, hom en pot trobar multitud d'exemples en el conjunt de l'obra de l'autor (Gregori Soldevila 2005: 260262), ja que es tracta d'un recurs d'ús recurrent, amb caràcter de tret distintiu, que ja podem rastrejar en aquesta primera novel.la, sobretot en el discurs del narrador intradiegètic primer, quan narra des de la seua particular i benintencionada visió la història de Larén i Glòria, però també quan es refereix a altres esdeveniments, com ara, en la manera de referir-se a la vida sexual del rajah de Bahamur, el qual «havia viscut amb bones relacions amb totes les senyores de la contrada, emparat per tot de lleis i per una concepció avançadíssima de la moral que tenen els barons d'aquelles terres» (p. 33).

\section{LES IRONIES DE SITUACIÓ}

En contraposició al caràcter intrínsecament lingüístic de la ironia verbal, la ironia de situació (Muecke 1969: 42-43) o referencial (Kerbrat-Orecchioni 1978: 1519) funciona mitjançant la disposició d'esdeveniments o elements d'una situació; és a dir, designa una contradicció observada en la realitat, no creada directament pel llenguatge ((Kerbrat-Orecchioni 1978: 17). Segons els diferents estudiosos o segons s'hi pose l'èmfasi en algun dels seus matisos, aquesta modalitat d'ironia ha estat designada amb diverses denominacions: ironia del destí o de la sort, ironia d'esdeveniments, etc.

La ironia d'esdeveniments es caracteritza per presentar una incongruència entre l'expectativa i l'esdeveniment (Muecke 1969: I02); en aquests casos, resulta irònic que, de manera imprevista, es frustren o es capgiren els propòsits o les esperances que animaven un fet o una acció. Així, per exemple, quan Larén no pot disparar el segon tret que ha de servir per a avisar Glòria que ell ha sortit indemne del duel, el neguit de pensar que la dona es suïcidarà, afligida per la seua mort, l'obliga a fer una carrera desesperada per a evitar-ho (p. 9I):

Una obsessió li repiquetejava els timpans i el cervell amb una freqüència de cor de gat: «La Glòria es matarà si només sent un tret: La Glòria creurà que el supervivent ha estat Donálvez».

[...] Conscient que cada minut que perdés podia fer més terrible la catàstrofe, va llençar la pistola i emprengué la davallada corrent com mai ho havia fet. 
Carme Gregori Soldevila

Els fonaments de la ironia caldersiana: La Glòria del doctor Larén

L'escena que troba en arribar a la granja, però, xoca irònicament amb la pressuposició de Larén, perquè la dona està celebrant amb el seu amant el desenllaç del duel: «va descobrir la Glòria i en Muraña abraçats, exterioritzant amb salts infantils una alegria candorosa» (p. 93). D'altra banda, aquest exemple funciona com una «ironie narrative», en terminologia proposada per Schoentjes (200I: 52), és a dir, com un procés de transformació que exigeix un temps de realització i que té com a resultat el contrari d'allò esperat. La ironia narrativa es contraposa a la «ironie picturale» (Schoentjes 200I: 52), que presenta dos elements en contradicció dins la mateixa escena, com podem observar en diferents exemples de l'episodi del duel. En primer lloc, contrasta irònicament el comportament dels contrincants amb la gravetat de l'escena: de camí al lloc triat per al duel, un d'ells porta "esmorzar per a dues persones» i l'altre, «un càntir ple d'aigua fresca» (p. 85); quan s'aturen a esmorzar, Larén enceta una conversa banal per trencar un silenci incòmode (p. 88):

\footnotetext{
Larén se sentí colpit el primer de la impolidesa continguda en el silenci que els voltava, i decidit a trencar-lo, enrogint-se prèviament de la seva imbecilitat, va preguntar sense pensar-s'hi: —Us agraden a vós les cireretes al conyac?
}

Resulta igualment inadequada, per absurda i gratuïta, la reacció de Larén quan l'arma no es dispara: «en el descontrol de la seva desesperança, el doctor va fer amb la boca un "pum!" infantil, insuficient, que no bastava a substituir, ni de bon tros, el soroll d'un tret» (p. 9I).

La ironia de situació pot fer patent que els esdeveniments no són el que semblen ser, com una mena de constatació que, en el fons, interroga la veritat dels fets (Schoentjes 200I: 74) i estableix una distància entre l'aparença i la realitat de les coses (Schoentjes 200I: 53). La Glòria del doctor Larén ens n'ofereix una àmplia varietat d'exemples. Així, les disfresses grotesques amb què el metge oculta la seua condició a la Glòria per no esverar-la instauren un contrast irònic entre allò que simula ser — «afinador de pianos, corredor d'escombres mecàniques, perit canaricultor, propagandista evangèlic, etc.» (p. 25) - i la professió i el motiu reals de les visites. O el fet que el narrador ironitze en subratllar les diferències, a l'hora de definir i valorar la casa de camp, entre el que creuen els personatges i el que ell afirma com a més ajustat a la realitat: «Va seduir-los l'aire que tenia, segons la Glòria, de bungalow i segons el doctor — sense ànim d'entaular polèmica- de barraca canadenca. Un esperit més equànime hauria declarat sense reserves que la casa semblava el galliner d'un gall aristocràtic, colossalista i antifuncional» (p. 66). Un altre exemple el tenim quan Larén, que és metge, converteix en simulació i aparença la seua professió, amb l'afegit degradant de rebaixar-ne la dignitat dels pacients: «cada dia dedicava més hores a jugar a metge i a malalts amb 
els conills, gallines i coloms de la casa» (p. 70). Basa igualment l'eficàcia irònica en la contraposició entre ésser i aparentar la delectació violenta del somni del narrador, si tenim en compte que prèviament se'ns havia presentat com a ferm defensor de «la bondat com a condició inherent a la naturalesa humana» (p. I8): "Aquella nit vaig esplaiar-me somniant que obria la panxa del meu conegut amb una estella de canya verda, i li treia els intestins i els molia amb un molinet de cafè» (p. IOo).

La ironia dramàtica és una categoria de la ironia de situació que, en paraules de Schoentjes, consisteix «en ceci que le spectateur —ou le lecteur- est au courant de faits que les personnages ignorent» (200I: 57). És a dir, en la ironia dramàtica, almenys un personatge no ha de ser conscient de la situació en què es troba, de manera que el seu comportament o les seues conviccions es basen en informacions, hipòtesis o fets que el lector, l'espectador o altres personatges saben erronis (Schoentjes 200I: 57). A La Glòria del doctor Larén en tenim un cas clar en l'escena en què Glòria creu que el paquet que porta Larén conté un preciós regal per a ella, en comptes de l'anestèsia que el doctor pretén administrar-li per sorpresa (pp. 28-29):

La Glòria rebé la visita de Larén, més tendre i galantejador, encara, que de costum. Duia un petit paquet suspès a la punta dels dits [...] A la vista del paquet, la Glòria cregué endevinar un món de sensacions finíssimes; girà els ulls en blanc, i pel blanc dels ulls entreveié com una gran cortina de pols d'ala de mosca que s'obria, i li deixava el cel al descobert. [...]

-Glòria, noia bonica. Acluca els ulls, i estèn els braços cap a mi...

La Glòria obeí. No sabia, en el seu èxtasi, si estirar el coll per encaixar un collaret de perles, o fer tremolar un dit ple d'ànsia de ser devorat per la boca d'un anell, o bé fer acabar la mà en punta per donar entrada a la polsera del cascavell meravellós. [...]

Mentrestant, Larén desfeia nerviosament el paquet, n'extreia una mascareta impregnada d'anestèsic i l'aplicava a la cara de la noia. La cortina caigué, cessà el cor de querubins i la Glòria s'esllavissà suaument en braços del doctor. En la seva fuga enfora de la vida, el dringueig estrident d'un cascavell li perforava els timpans.

El desenllaç de la novel-la, amb la Glòria i el seu amant afectats per la sarna, se'ns presenta, per part del doctor Larén, com una manifestació de la variant específica de la ironia del destí: "No sé si alguna vegada heu tingut el sentiment d'una compensació autèntica, d'equilibri, que les coses desballestades tornin al seu lloc per l'engranatge d'una fatalitat que està molt per damunt nostre. Jo aleshores sentia això» (pp. II3-II4). Per al protagonista masculí, aquest final s'ha d'entendre com «el càstig dels dolents» (II5); d'altra banda, ell té una confiança absoluta que aquest càstig ha d'anar acompanyat del corresponent premi a la víctima innocent, que és ell mateix: "Confio cegament que aquest premi que reclameu es produirà. No sospito gens per on ni com vindrà, però vull col-laborar amb l'atzar, ajudar-lo en aquesta obra d'estricta $\mathrm{i}$ indefugible justícia. Mireu, he comprat un bitllet sencer per a la rifa extraordinària

Caplletra 60 (Primavera, 2016), pp. 163-182 
Carme Gregori Soldevila

Els fonaments de la ironia caldersiana: La Glòria del doctor Larén

de demà.[...]. Aquest acte és una veritable cita al destí. Si aquesta justícia fatalista que sospiteu és certa, acudirà a la cita» (p. II6). I, en efecte, la convicció de Larén es veurà confirmada tres dies més tard: «Resultava que sí. Que la sort havia acudit a la seva cita i havia guanyat la rifa» (p. II9). La ironia del destí o de la sort pressuposa l'existència d'una força o entitat superior que es complau a frustrar les esperances o els projectes dels personatges, a capgirar-ne irònicament les expectatives; en aquest cas, la felicitat que Glòria pensava assolir a partir de la fugida amb l'amant es veurà enterbolida per la infecció sarnosa, mentre que Larén, que semblava condemnat a la desgràcia, veurà canviar radicalment la seua sort. Tot i això, cal considerar que el desenllaç de La Glòria del doctor Larén, més que una ironia del destí el que ens proposa és una paròdia de la ironia del destí, com analitzarem tot seguit, en l'apartat dedicat a la paròdia.

\section{LES PARÒDIES}

Per a Linda Hutcheon, la paròdia «is a form of imitation, but imitation characterized by ironic inversion» $\mathrm{o}$, dit d'una altra manera, «repetition with critical distance, which marks difference rather than similarity» (1985: 6). Amb aquesta concepció, Hutcheon és, entre els teòrics de la paròdia, l'autora que estableix un nexe més estret entre paròdia i ironia, en subratllar-ne la distància crítica com a tret caracteritzador. D'altra banda, a diferència de la concepció restrictiva de la paròdia que sosté Genette (1982), per a Hutcheon, la paròdia té un caràcter àmpliament inclusiu; qualsevol discurs codificat pot ser objecte de paròdia, de manera que aquesta pot tenir com a text de referència tant una obra concreta com les convencions d'un gènere, un estil, un moviment, etc. (Hutcheon 1985: I8).

La ironia del destí pressuposa un ordre fatalista del món, l'existència d'unes forces irracionals i misterioses, incontrolables, que fixen capriciosament la sort dels individus, sense que aquests se'n puguen defensar. En la versió paròdica que ens n'ofereix la novel.la de Calders, el doctor Larén substitueix el misteri i la irracionalitat per una lògica plenament racionalitzada que únicament es basa en l'existència prèvia d'una tradició de textos que han fet servir la ironia del destí per a elaborar una lliçó moral, segons la qual el mal rep el seu càstig i el bé, la seua recompensa. L'atzar cec que governa la ironia del destí, implacable i inquietant precisament per ser fortuït i imprevisible, es torna una llei de compliment assegurat, gairebé indefectible, posant al descobert la seua conversió en un tòpic. Les conseqüències moralitzants que se'n desprenen també han estat sotmeses a la reelaboració paròdica: la restitució de la pèrdua i la compensació del dany moral sofert per la víctima es trasllada, amb el pre- 
mi de la rifa, al terreny del materialisme més elemental i estricte. El motiu de l'atzar o del destí fatal serà recurrent en l'obra de maduresa de Calders, sempre en la línia paròdica encetada en La Glòria del doctor Larén, presentat com una entitat familiar i quotidiana, plenament acceptada pels personatges, que ha perdut el caràcter intangible i transcendent i és designada de manera directa i desdramatitzada amb termes com la Providència o el Destí (Melcion I986: 73-74).

La paròdia és un dels principals mecanismes de la poètica caldersiana (Gregori Soldevila 2005). La inversió irònica de les convencions de gèneres, tòpics i estils diversos funciona, en l'obra de Calders, com un mitjà que permet posar al descobert el caràcter arbitrari, culturalment condicionat, de la nostra percepció del món i de les imatges que se'n generen. El resultat aboca, en últim terme, a una indagació sobre les possibilitats i els límits d'aprehensió de la realitat i sobre el concepte mateix de realitat.

A més de la paròdia de la ironia del destí, a La Glòria del doctor Larén n'apareixen altres casos, com ara, el tractament de l'afició a la caça per part del protagonista masculí. El personatge prepara un escenari i uns mitjans que s'ajusten escrupolosament a les convencions prescrites pel tòpic. De fet, Larén construeix un decorat amb els elements evocadors més estereotipats, que incorpora fins i tot els succedanis d'uns trofeus inexistents (p. 69):

\footnotetext{
Va fer-se arreglar una de les habitacions lliures de la casa inspirant la decoració amb temes cinegètics. Hi havia un armari per a les escopetes, panòplies amb armes curtes i eines d'esquarterament, una catifa reduïda feta amb la pell d'un exòtic ós formiguer i diversos plafons compostos amb caps d'animals dissecats, comprats a sota preu en el magatzem d'un teatre en liquidació. Tenia també una reproducció magnífica del cap del brau que va matar "Joselito» i una caseta de gos.
}

L'ambientació pot crear una atmosfera adequada, però no és en absolut suficient per a assolir els objectius desitjats; Larén veurà frustrades les seues expectatives cinegètiques en un territori on «la caça escasseja prou notablement perquè un caçador novell s'hi descoratgi» (p. 69) i optarà per una alternativa, clarament paròdica per la degradació del model (pp. 69-70):

avorrit d'esperar hores i hores l'aparició d'unes perdius i uns conills imaginaris, va dedicar les seves activitats a un canyissar de torrentera que estava plagat de llangardaixos. [...] El doctor s'hi acostava cautament i entre canya i canya n'engegava unes mortíferes perdigonades.

La incongruència irònica de la versió paròdica es veurà reforçada per la incoherència d'un gos amb vocació vegetariana (p. 69):

un ca d'ulls tristos, baix d'orelles i de cua, al qual l'instint li proscrivia vigorosament l'ús de la carn en la seva alimentació, per patir a la callada i ignorat de tothom una colitis ulcerosa,

Caplletra 60 (Primavera, 2016), pp. 163-182 
Carme Gregori Soldevila

Els fonaments de la ironia caldersiana: La Glòria del doctor Larén

el qual fa les funcions assignades a contracor (p. 70):

el gos es dirigia fastiguejat cap al conglomerat constituït per la pasta de les víctimes, n’agafava una mossada a l'atzar, amb un gest de repugnància ben marcat, i retornava remenant oficiosament la cua.

L'episodi del duel, amb una constant divergència entre allò que és esperable segons la preceptiva del model i el comportament dels personatges, també ha de ser entès com una paròdia que rebaixa la gravetat dels referents i n'elimina el caràcter dramàtic. L'al.lusió a les convencions del gènere objecte d'imitació són explícites; en primer lloc, quan els protagonistes constaten que no saben «com començar el joc escènic del duel» (p. 89) o fan referència al «sistema més acreditat» (p. 90). El sentit paròdic es fa evident sobretot en el moment en què Donálvez incorpora un detall inútil i teatral a allò que el narrador no dubta a qualificar de mise en scène: "Calia, en virtut de no sé quines misterioses exigències, que els duelistes s'aixequessin el coll de les americanes» (p. 90).

\section{CONCLUSIONS}

La literatura de Pere Calders té la ironia com a tret distintiu essencial; el conjunt de l'obra de l'autor exhibeix de manera sostinguda i recurrent els recursos irònics, en tota l'àmplia i variada gamma de possibilitats: des de les ironies verbals fins a les de situació, passant per les paròdies i les ironies de caràcter metaficcional (Gregori Soldevila 20I2: 46-53). La ironia va ser l'opció triada com a mitjà per a escapar de la pesantor i de l'opacitat d'un món tràgic i grotesc. L'anàlisi detallada de la ironia en La Glòria del doctor Larén ens ha permès comprovar de manera incontestable que, en aquesta primera novel.la - $\mathrm{i}$, en paral.lel a l'ús que en fa en els contes de la mateixa època-Calders posa les bases de la seua poètica, amb la ironia com a element central. Tots els mecanismes irònics que caracteritzaran l'obra de maduresa hi són presents; potser encara, en general, en un estadi d'elaboració i de refinament menor del que trobarem en obres posteriors, però ja amb el caràcter, les funcions i l'estil que identifiquem com a netament caldersià. Els estudis precedents havien advertit les connexions existents entre La Glòria del doctor Larén i Ronda naval sota la boira, la novel.la que definirà millor que cap altra obra l'univers caldersià, en relació a la importància que assoleix en ambdues el component metaficcional, netament irònic (Campillo 1996; Melcion 1996 i 2003; Aulet 1997; Balaguer 2003; Martínez Gil 2003). Ara, hem pogut demostrar que també la resta de procediments irònics habituals en l'autor apareixen 
en aquesta obra inicial: metaficció irònica; les ironies del narrador en l'exercici de les funcions que li són pròpies; lítotes, hipèrboles, antífrasis, oxímorons i altres recursos de la ironia verbal que, en gran mesura, incideixen en l'exploració del llenguatge per fer-ne aflorar els sentits latents i mostrar-ne els usos estereotipats; diverses modalitats de la ironia de situació o d'esdeveniments que posen al descobert les incongruències $\mathrm{i}$ el trencament d'expectatives i pressuposicions que guien la visió humana de la realitat; i les paròdies, com a mitjà idoni per a denunciar els codis culturals que sostenen la nostra aprehensió del món i que imposen, en definitiva, un distanciament higiènicament irònic com a filtre en els mecanismes de percepció que fem servir.

Carme Gregori Soldevila Universitat de València

Carme.Gregori-Soldevila@uv.es

\section{REFERÈNCIES BIBLIOGRÀFIQUES}

Aulet, J. (1997) «Pere Calders i la seva faceta de novel-lista (A propòsit de La Glòria del doctor Larén i Ronda naval sota la boira)», dins R. Cabré (ed.), Pere Calders $o$ la passió de contar, Barcelona/Vic, Departament de Filologia Catalana de la Universitat de Barcelona / Eumo Editorial, pp. 67-84.

Balaguer, J. M. (2003) «Calders i l'autor déu», dins C. Puig Molist (ed.), Pere Calders i el seu temps, Barcelona, Publicacions de l'Abadia de Montserrat, pp. 335-350.

Ballart, P. (1994) Eironeia. La figuración irónica en el discurso literario moderno, Barcelona, Quaderns Crema.

Bath, A. (1987) Pere Calders: ideari i ficció, Barcelona, Edicions 62.

Calders, P. (1994) La Glòria del doctor Larén, Barcelona, Edicions 62.

- (2013) La maleta extraviada. Més cartes a Joan Triadú, Barcelona, Publicacions de l'Abadia de Montserrat.

Campillo, M. (1996) «La mirada de Pere Calders», dins M. Casacuberta i M. Gustà (eds.), De Rusiñol a Monzó: humor i literatura, Barcelona, Publicacions de l'Abadia de Montserrat, pp. IO7-I20.

Cardona, O. (1937) «Pere Calders: "La Glòria del doctor Larén"”, Mirador, 4IO, p. 5.

Genette, G. (1972) Figures III, París, Seuil.

- (1982) Palimpsestes. La littérature au second degré, París, Seuil. 
Carme Gregori Soldevila

Els fonaments de la ironia caldersiana: La Glòria del doctor Larén

- (1987) Seuils, París, Seuil.

Gregori Soldevila, C. (2005) Pere Calders: tòpics i subversions de la tradició fantàstica,

Barcelona, Publicacions de l'Abadia de Montserrat.

- (2012) «Pere Calders, una poètica irònica per a un segle desolat», L'Avenç, 382, pp. 46-53.

Hutcheon, L. (1985) A Theory of Parody. The Teaching of Twentieth-Century Arts Forms, Londres / Nova York, Routledge.

Kerbrat-Orecchioni, C. (1978) «Problèmes del'ironie», Travauxdu Centre de recherches linguistiques et sémiologiques de Lyon, 2, Presses Universitaires de Lyon, pp. Io-46.

Martínez GiL, V. (2003) «Consciència i moralitat en la narrativa de Pere Calders», dins C. Puig Molist (ed.), Pere Calders i el seu temps, Barcelona, Publicacions de l'Abadia de Montserrat, pp. 199-2I4.

Melcion, J. (1986) «Cròniques de la veritatoculta», de Pere Calders, Barcelona, Empúries.

- (1996) «Del conte a la novel-la: Pere Calders i la ficció de la ficció», Catalan Review, vol. X, I-2, pp. 239-259.

— (2003) «Èxodes, viatges, desvaris i naufragis», dins C. Puig Molist (ed.), Pere Calders i el seu temps, Barcelona, Publicacions de l'Abadia de Montserrat, pp. 43-66.

Muecke, D. C. (1969) The Compass of Irony, Londres, Methuen.

- (1970) Irony, Londres, Methuen.

Pons, A. (1998) Pere Calders, veritat oculta, Barcelona, Edicions 62.

Schoentjes, P. (20or) Poétique de lironie, París, Seuil.

Sperber, D. \& D. Wilson (1978) «Les ironies comme mentions», Poétique, 36, pp. $399-412$.

Triadú, J. (1963) «Comentari mensual», Serra d’Or, iv, núm. 7, pp. 27-28.

Vallverdú, F. [Ramon Roig] (196I) «L'obra de Pere Calders», Horitzons, 4, pp. 3I-36.

— (1994) «Preàmbul», dins P. Calders, La Glòria del doctor Larén, Barcelona, Edicions 62, pp. 7-I2. 